\title{
NILAI TAMBAH AGROINDUSTRI PENGOLAHAN KOMODITAS PANGAN UNGGULAN DI KECAMATAN SELAPARANG KOTA MATARAM
}

\author{
Anwar ${ }^{*}$, Bambang Dipokusumo, Suparmin, dan Hirwan Hamidi \\ Program Studi Agribisnis Fakultas Pertanian Universitas Mataram \\ ${ }^{*}$ Korespondensi: anwar@unram.ac.id
}

Diterima 3 November 2018 / Disetujui 29 November 2018

\begin{abstract}
ABSTRAK
Kota Mataram merupakan salah satu sentra pemasaran produk-produk hasil usaha agroindustri. Kecamatan Selaparang merupakan salah satu kecamatan yang mampu menghasilkan produk hasil usaha agroindustri melalui pengolahan komoditas pangan unggulan. Tujuan dilaksanakannya pengabdian pada masyarakat ini adalah untuk: (1) meningkatkan pengetahuan dan keterampilan petani tentang pentingnya nilai tambah komoditas unggulan; (2) menjalin kerjasama kemitraan antara petani dan pengusaha lokal dalam pemasaran hasil olahan komoditas pangan unggulan; dan (3) meningkatkan harga jual dan nilai tambah hasil olahan komoditas unggulan. Pelaksanaan menggunakan metode pendidikan orang dewasa (andragogy) yaitu merekontruksi pengetahuan dan pengalaman peserta secara sistematis agar memberikan manfaat praktis meningkatkan pengetahuan dan keterampilannya. Pelaksanaan terdiri atas penyuluhan dan pendampingan. Materi penyuluhan adalah teknik pengolahan berbagai komoditas unggulan, teknik pengemasan produk dan pemasaran, sementara materi pendampingan adalah jalinan kerjasama kemitraan antara petani/pengusaha agroindustri dengan pengusaha lokal untuk mendapatkan jaminan bahwa produk yang dihasilkan memiliki kepastian tersedianya pembeli dengan harga yang lebih tinggi. Hasil kegiatan diperoleh nilai tambah agroindustri pengolahan komoditas pangan unggulan yang dilakukan di Kelurahan Rembiga Kecamatan Selaparang Kota Mataram, untuk produk tortila menghasilkan nilai tambah sebesar Rp $36.349 / \mathrm{kg}$ bahan baku $(53,62 \%)$, produk rengginang menghasilkan nilai tambah sebesar $\mathrm{Rp}$ $32.330 / \mathrm{kg}$ bahan baku (50,07\%), produk emping menghasilkan nilai tambah sebesar Rp $21.611 / \mathrm{kg}$ bahan baku $(50,85 \%)$, produk kripik ubi kayu menghasilkan nilai tambah sebesar Rp 14.875/kg bahan baku (53,22\%).
\end{abstract}

Kata Kunci: agroindustri, nilai tambah, komoditas unggulan

\section{PENDAHULUAN}

Pembangunan pertanian di Indonesia diarahkan menuju pembangunan pertanian yang berkelanjutan (sustainable agriculture), sebagai bagian dari implementasi pembangunan berkelanjutan (sustainable development). Pada Rencana Pembangunan Jangka Menengah Nasional (RPJMN) tahun 2015-2019, 
sektor pertanian masih menjadi sektor penting karena berperan dalam pembangunan perekonomian nasional. Tujuan Kementerian Pertanian tahun 2015-2019 adalah: (1) Pencapaian swasembada pangan padi, jagung dan kedelai serta peningkatan produksi gula dan daging, (2) peningkatan diversifikasi pangan, (3) peningkatan komoditas bernilai tambah dan berdaya saing dalam memenuhi pasar ekspor dan substitusi impor, (4) penyediaan bahan baku bioindustri dan bioenergi, (5) peningkatan pendapatan keluarga petani, serta (6) akuntabilitas kinerja aparatur pemerintah yang baik (Kementrian Pertanian, 2015).

Dalam upaya mewujudkan ketahanan pangan saat ini masih dihadapkan kepada tantangan yang cukup berat. Tantangan dimaksud adalah jumlah penduduk yang terus bertambah sehingga memerlukan penyediaan pangan yang besar dan beragam. Disisi lain, masih terjadi permasalahan substantif dalam peningkatan produksi pangan yaitu antaralain, alih fungsi lahan, rusaknya jaringan irigasi, mahalnya upah tenaga kerja pertanian serta kurangnya peralatan mekanisasi pertanian, masih tingginya susut hasil, belum terpenuhinya kebutuhan pupuk dan benih sesuai rekomendasi spesifik lokal serta belum memenuhi tempat, harga komoditas pangan jatuh dan sulitnya memasarkan hasil pada saat panen raya (www.pertanian.go.id)

Dalam mengatasi permasalahan tersebut, kementrian pertanian telah menetapkan Upaya Khusus Peningkatan Produksi Padi, Jagung dan Kedelai, melalui kegiatan rehabilitasi jaringan irigasi tersier dan kegiatan pendukung lainnya, antara lain, pengembangan jaringan irigasi, optimasi lahan, Gerakan Penerapan
Pengelolaan Tanaman Terpadu (GP-PTT), penyediaan sarana dan prasarana pertanian dan pengawalan/pendampingan yang diberikan kepada masyarakat kelompok tani yang berusahatani tanaman pangan (www.pertanian.go.id).

Provinsi Nusa Tenggara Barat dalam lima tahun terakhir (2010-2015) mengalami peningkatan produksi padi, jagung dan kedele yaitu meningkat $36,72 \%$ dari 1,77 juta ton. Setidaknya ada lima alasan utama rasa optimisme tersebut, yaitu: (1) industri pengolahan mampu mengubah keunggulan komparatif menjadi keunggulan kompetitif, yang akhirnya akan memperkuat daya saing produk; (2) produk agroindustri memiliki nilai tambah dan pasar yang besar sehingga dapat mempengaruhi pertumbuhan perekonomian nasional; (3) agroindustri memiliki keterkaitan yang besar baik ke hulu maupun ke hilir, sehingga mampu menarik kemajuan sektor lain; (4) memiliki basis bahan baku lokal (keunggulan komparatif) sehingga terjamin keberlanjutannya; dan (5) berpeluang mengubah struktur ekonomi nasional dari pertanian ke industri (Supriyati dan Tarigan, 2008).

Dengan demikian, pembangunan disektor industri merupakan perioritas utama pembangunan ekonomi tanpa mengabaikan pembangunan di sektor lain. Selain itu, sektor intustri mampu mempercepat pertumbuhan ekonomi melalui peningkatan nilai tambah komoditas pangan unggulan tersebut. Berkembangnya sektor industri memberikan efek domino terhadap sektor lainnya sehingga terjadi percepatan pertumbuhan ekonomi regional, khususnya di Provinsi Nusa Tenggara Barat. 
Seiring berjalannya waktu, Kecamatan Selaparang Kota Mataram merupakan pusat pertumbuhan ekonomi baru di Provinsi Nusa Tenggara Barat yang ini ditunjukkan oleh berkembangnya sektor industri dan jasa. Usaha pengolahan hasil produk pertanian, peternakan dan perikanan dari tahun ketahun terus mengalami kemajuan yang cukup signifikan. Kualitas dan kuantitas dari produk hasil olahan ini terus mengalami peningkatan yang ditandai dengan semakin banyaknya permintaan baik lokal maupun dari luar daerah. Berbagai produk olahan yang ada antara lain; keripik pisang, keripik ubi kayu, krupuk ceker, telur asin, abon, dodol nangka dan lain-lain. Salah satu strategi yang dapat ditempuh untuk mengembangkan perekonomian daerah adalah pengembangan agroindustri melalui kelompok-kelompok pengolahan hasil (Disperindag, 2014).

Dengan adanya industri yang mengubah bentuk primer menjadi produk baru yang lebih tinggi nilai ekonomisnya setelah melalui proses pengolahan, maka akan dapat memberikan nilai tambah karena dikeluarkannya biaya-biaya sehingga terbentuk harga baru yang lebih tinggi dan keuntungannya lebih besar bila dibandingkan tanpa melalui proses pengolahan. Berdasarkan uraian di atas, maka sangat penting dilakukan pengabdian masyarakat dengan topik nilai tambah agroindustri komoditas pangan unggulan di kecamatan selaparang kota mataram.

\section{METODE KEGIATAN}

Pelaksanaan kegiatan

menggunakan pendekatan jejaring kerjasama antara tim pelaksana dengan kelompok agroindustri di Kelurahan Rembiga Kecamatan Selaparang Kota Mataram. Pelaksanaan penyuluhan menggunakan metode pendidikan orang dewasa (andragogy), yaitu suatu metode pembebasan dengan merekonstruksi pengetahuan dan pengalaman pengusaha agroindustri menjadi pengetahuan dan keterampilan yang berstruktur dan bermanfaat dalam penyelenggaraan manajemen industri pengolahan komoditas pangan unggulan.

Untuk mengetahui besarnya nilai tambah yang diperoleh dari produk tortila jagung, rengginang jagung, emping jagung dan keripik ubi kayu dapat dihitung melalui data primer yang diperoleh dari responden yang kemudian dianalisis dengan menggunakan metode Hayami yang disajikan pada Tabel 1 (Said, G., 2005): 
Tabel 1. Analisis nilai tambah dengan metode Hayami

\begin{tabular}{|c|c|c|}
\hline No & Variabel & Nilai \\
\hline \multicolumn{3}{|c|}{ 1. Output, Input dan Harga } \\
\hline & a. $\quad$ Produksi $(\mathrm{kg})$ & A \\
\hline & b. Bahan Baku (liter) & $\mathrm{B}$ \\
\hline & c. Tenaga Kerja (HKO) & $\mathrm{C}$ \\
\hline & d. Faktor Konversi & $d=a / b$ \\
\hline & e. Koefesien Tenaga Kerja (HKO) & $e=c / b$ \\
\hline & f. Harga Output Rata-Rata (Rp/kg) & $\mathrm{F}$ \\
\hline & g. Upah Rata-Rata Tenaga Kerja (Rp/HKO) & $\mathrm{G}$ \\
\hline \multicolumn{3}{|c|}{ 2. Penerimaan dan Keuntungan } \\
\hline & h. Harga Bahan Baku (Rp/liter) & $\mathrm{H}$ \\
\hline & i. Sumbangan Input Lain (Rp/Kg) & 1 \\
\hline & j. $\quad$ Nilai Produksi (Rp/kg) & $j=d \times f$ \\
\hline & k1. Nilai Tambah (Rp/Kg) & $k 1=j-i-h$ \\
\hline & k2. Rasio Nilai Tambah (\%) & $k 2=(k 1 / j) \times 100 \%$ \\
\hline & I1. Imbalan Tenaga Kerja (Rp/HKO) & $11=\mathrm{e} \times g$ \\
\hline & 12. Rasio Bagian Tenaga Kerja (\%) & $12=(11 / k 1) \times 100 \%$ \\
\hline & m1. Keuntungan & $\mathrm{m} 1=\mathrm{k} 1-\mathrm{l} 1$ \\
\hline & m2. Tingkat Keuntungan (\%) & $\begin{array}{c}m 2=(m 1 / j) x \\
100 \%\end{array}$ \\
\hline \multicolumn{3}{|c|}{ 3. Balas Jasa Pemilik Faktor-Faktor Produksi } \\
\hline & n. Margin Keuntungan & $n=j-h$ \\
\hline & n1. Pendapatan Tenaga Kerja (\%) & $\mathrm{n} 1=(\mathrm{I} 1 / \mathrm{n}) \times 100 \%$ \\
\hline & n2. Sumbangan Input Lain (\%) & $\mathrm{n} 2=(\mathrm{i} / \mathrm{n}) \times 100 \%$ \\
\hline & n3. Keuntungan Kegiatan Produksi (\%) & $\begin{array}{c}n 3=(m 1 / \mid 1) x \\
100 \%\end{array}$ \\
\hline
\end{tabular}




\section{HASIL DAN PEMBAHASAN}

\section{Aliran Proses Produksi}

Proses pembuatan emping, tortila, rengginang dan kripik ubi kayu seperti disajikan pada Gambar 1.

\section{Analisis Nilai Tambah}

Besarnya tambahan nilai (manfaat) yang diperoleh sebagai akibat dari penggunaan sejumlah biaya dalam proses pengolahan jagung dan ubi kayu menjadi produk tortila jagung, rengginang jagung, emping jagung dan kripik ubi kayu. Rincian analisis nilai tambah pada agroindustri kelompok pengolahan hasil pertanian di Kelurahan Rembiga Kecamatan Selaparang Kota Mataram disajikan pada Tabel

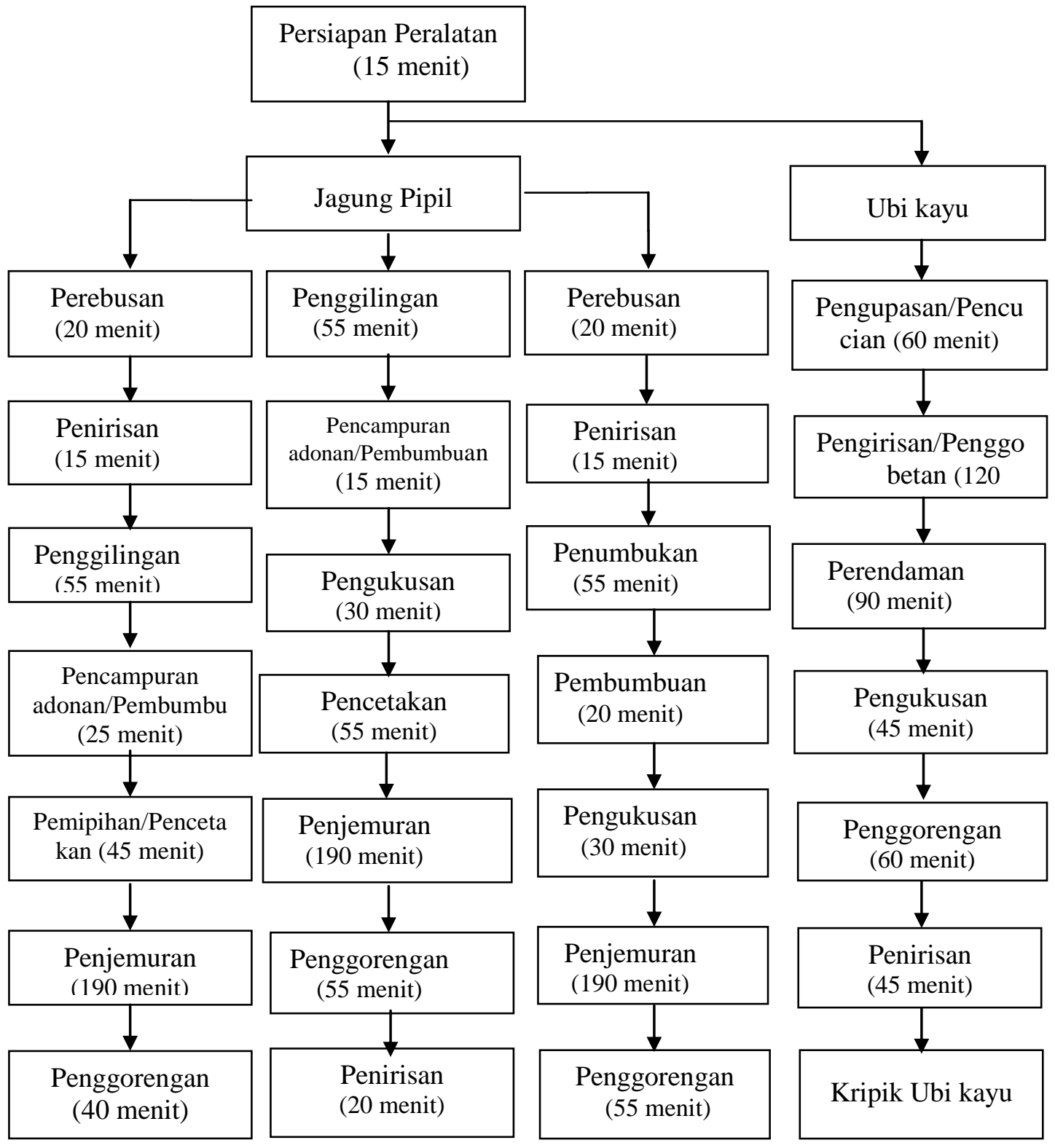

Gambar 1. Proses pembuatan emping, tortila, rengginang dan kripik ubi kayu 
Tabel 2. Analisis nilai tambah pada agroindustri pengolahan komoditas pangan unggulan di Kecamatan Selaparang kota Mataram

\begin{tabular}{|c|c|c|c|c|c|}
\hline \multirow[b]{2}{*}{ No } & \multirow[b]{2}{*}{ Variabel } & \multicolumn{4}{|c|}{ Nilai Olahan Komoditas } \\
\hline & & Tortila & Rengginang & Emping & $\begin{array}{l}\text { Kripik } \\
\text { Ubikayu }\end{array}$ \\
\hline \multirow[t]{8}{*}{1} & Output, Input dan Harga & & & & \\
\hline & a. $\quad$ Produksi (Kg) & 5,28 & 4,13 & 5,67 & 4,44 \\
\hline & b. Bahan Baku (Kg) & 3,11 & 2,88 & 4,67 & 5,88 \\
\hline & c. Tenaga Kerja (HKO) & 2,00 & 2,00 & 2,00 & 2,00 \\
\hline & d. Faktor Konversi (Kg/kg BB) & 1,69 & 1,43 & 1,21 & 0,76 \\
\hline & $\begin{array}{l}\text { Koefesien Tenaga Kerja (HKO/kg } \\
\text { e. } \mathrm{BB} \text { ) }\end{array}$ & 0,64 & 0,70 & 0,43 & 0,34 \\
\hline & f. Harga Output Rata-Rata $(\mathrm{Rp} / \mathrm{kg})$ & 40000 & 45000 & 35000 & 37000 \\
\hline & $\begin{array}{l}\text { g. Upah Rata-Rata Tenaga Kerja } \\
\text { (Rp/HKO) }\end{array}$ & 30000 & 30000 & 30000 & 30000 \\
\hline \multirow[t]{12}{*}{2} & Penerimaan dan Keuntungan & & & & \\
\hline & h. Harga Bahan Baku (Rp/Kg) & 5000,00 & 5000,00 & 5000,00 & 3000,00 \\
\hline & i. Sumbangan Input Lain (Rp/Kg BB) & 6441,77 & 27234,78 & 15889,29 & 0072,34 \\
\hline & $\begin{array}{l}\text { i.1 Sumbangan Bhn. Penolong (Rp/kg } \\
\text { BB) }\end{array}$ & 5558,23 & 5669,57 & 1960,71 & 497,87 \\
\hline & $\begin{array}{l}\text { i.2 Sumbangan Bhn. Pendukung } \\
(\mathrm{Rp} / \mathrm{kg} \mathrm{BB})\end{array}$ & 0883,53 & 21565,22 & 13928,57 & 9574,47 \\
\hline & j. $\quad$ Nilai Produksi (Rp/Kg BB) & 7791,16 & 64565,22 & 42500,00 & 7946,81 \\
\hline & k1. Nilai Tambah (Rp/Kg BB) & $\beta 6349,40$ & 32330,43 & 21610,71 & 4874,47 \\
\hline & k2. Rasio Nilai Tambah (\%) & 53,62 & 50,07 & 50,85 & 53,22 \\
\hline & I1. Imbalan Tenaga Kerja (Rp/Kg BB) & 9277,11 & 20869,57 & 12857,14 & 0212,77 \\
\hline & 12. Rasio Bagian Tenaga Kerja (\%) & 53,03 & 64,55 & 59,49 & 68,66 \\
\hline & m1 Keuntungan (Rp/Kg BB) & 7072,29 & 11460,87 & 8753,57 & 4661,70 \\
\hline & m2 Tingkat Keuntungan (\%) & 25,18 & 17,75 & 20,60 & 16,68 \\
\hline \multirow[t]{5}{*}{3} & $\begin{array}{l}\text { Balas Jasa Pemilik Faktor-Faktor } \\
\text { Produksi }\end{array}$ & & & & \\
\hline & n1. Bahan Baku (\%) & 7,38 & 7,74 & 11,76 & 10,73 \\
\hline & n2. Pendapatan Tenaga Kerja (\%) & 28,44 & 32,32 & 30,25 & 36,54 \\
\hline & n3. Sumbangan Input Lain (\%) & 39,00 & 42,18 & 37,39 & 36,04 \\
\hline & $\begin{array}{l}\text { Keuntungan Kegiatan Produksi } \\
\text { (\%) }\end{array}$ & 25,18 & 17,75 & 20,60 & 16,68 \\
\hline
\end{tabular}


Pengolahan jagung dan ubi kayu menjadi produk tortila jagung, rengginang jagung, emping jagung dan kripik ubi kayu dipengaruhi oleh jumlah produksi, bahan baku yang digunakan dan tenaga kerja yang terlibat. Selain itu, harga baik harga produksi, harga bahan baku dan upah tenaga kerja juga berpengaruh dalam perhitungan nilai tambah produk gula aren dan menentukan besar kecilnya keuntungan yang akan diterima oleh pelaku usaha.

Nilai tambah merupakan selisih antara nilai produksi dikurangi dengan harga bahan baku (BB) dan sumbangan input lain (bahan penolong dan bahan pendukung). Tabel 2 menunjukan bahwa pada produk tortila jagung menghasilkan nilai tambah sebesar Rp 36.349/kg BB, artinya bahwa setiap $1 \mathrm{~kg}$ bahan baku sebesar Rp 5.000 dan biaya sebesar Rp. 26.442 (sumbangan input lainya) untuk setiap bahan baku setelah diolah menjadi 1,69 kg tortila jagung dengan nilai produksi (output) tortila jagung yang dihasilkan Rp 67.791 dapat meningkatkan nilai tambah sebesar Rp 36349/kg BB dengan rasio nilai tambah sebesar 53,62 $\%$. Untuk imbalan tenaga kerja sebesar Rp 19.277 yang diperoleh dari koefiensi tenaga kerja sebesar $\mathrm{Rp}$ 0,64 dikalikan dengan upah tenaga kerja sebesar $\mathrm{Rp}$ 30.000, sedangkan untuk keuntungan tortila jagung diproleh dari nilai tambah dikurangi dengan imbalan tenaga kerja sebesar $\mathrm{Rp} 17.072$ dengan tingkat keuntungan $25,18 \%$.

Pada produk rengginang jagung menghasilkan nilai tambah sebesar $\mathrm{Rp}$ 32.330/kg BB, artinya bahwa setiap $1 \mathrm{~kg}$ bahan baku sebesar Rp 5.000 dan biaya sebesar Rp 27.235 (sumbangan input lainya) untuk setiap bahan baku setelah diolah menjadi $1,43 \mathrm{~kg}$ rengginang jagung dengan nilai produksi (output) yang dihasilkan Rp 64.565 dapat meningkatkan nilai tambah sebesar Rp $32.330 / \mathrm{kg}$ BB dengan rasio nilai tambah sebesar 50,07 $\%$. Untuk imbalan tenaga kerja sebesar Rp 20.870 yang diperoleh dari koefiensi tenaga kerja sebesar $\mathrm{Rp}$ 0,70 dikalikan dengan upah tenaga kerja sebesar Rp 30.000, sedangkan untuk keuntungan rengginang jagung diproleh dari nilai tambah dikurangi dengan imbalan tenaga kerja yaitu sebesar Rp 11.461 dengan tingkat keuntungan $17,75 \%$.

Pada produk emping jagung menghasilkan nilai tambah sebesar $\mathrm{Rp}$ 21.611/kg BB, artinya bahwa setiap $1 \mathrm{~kg}$ bahan baku sebesar Rp 5.000 dan biaya sebesar Rp 15.889 (sumbangan input lainya) untuk setiap bahan baku setelah diolah menjadi 1,21 kg emping jagung dengan nilai produksi yang dihasilkan $\mathrm{Rp}$ 42.500 dapat meningkatkan nilai tambah sebesar Rp 21.611/kg BB dengan rasio nilai tambah sebesar 50,85\%. Untuk imbalan tenaga kerja sebesar Rp 12.857 yang diperoleh dari koefiensi tenaga kerja sebesar Rp 0,43 dikalikan dengan upah tenaga kerja sebesar Rp 30.000, sedangkan untuk keuntungan emping jagung diproleh dari nilai tambah dikurangi dengan imbalan tenaga kerja sebesar $\mathrm{Rp} 8.754$ dengan tingkat keuntungan 20,60\%.

Pada produk kripik ubi kayu menghasilkan nilai tambah sebesar Rp 14.875/kg BB, artinya bahwa setiap $1 \mathrm{~kg}$ bahan baku sebesar Rp 3.000 dan biaya sebesar Rp 10.072 (sumbangan input lainya) untuk setiap bahan baku setelah diolah menjadi 0,76 kg kripik ubi kayu dengan nilai produksi (output) yang dihasilkan Rp 27.947 dapat meningkatkan 
nilai tambah sebesar Rp 14.875/kg BB dengan rasio nilai tambah sebesar $53,22 \%$. Untuk imbalan tenega kerja sebesar $\mathrm{Rp}$ 10.213 yang diperoleh dari koefiensi tenaga kerja sebesar $\mathrm{Rp}$ 0,34 dikalikan dengan upah tenaga kerja sebesar $\mathrm{Rp}$ 30.000, sedangkan untuk keuntungan tortila jagung diproleh dari nilai tambah dikurangi dengan imbalan tenaga kerja sebesar $\mathrm{Rp} 4.662$ dengan tingkat keuntungan $16,68 \%$.

\section{KESIMPULAN DAN SARAN}

\section{Kesimpulan}

Terjalinnya kerjasama kemitraan antara pengusaha agroindustri dan pengusaha lokal dalam pemasaran hasil olahan komoditas pangan unggulan. Berkembangnya industri rumahtangga yang bergerak dalam pengolahan komoditas pangan unggulan.

Struktur pembiayaan pada agroindustri pengolahan komoditas pangan unggulan terdiri dari yaitu: (a) biaya rata-rata bahan baku per proses produksi produk tortila sebesar Rp 15.563, produk rengginang sebesar $\mathrm{Rp} 14.375$, produk emping sebesar Rp 23.333 dan produk kripik ubi kayu sebesar Rp 17.625; (b) biaya rata-rata bahan penolong dan pendukung per proses produksi produk tortila jagung bahan penolongnya sebesar Rp 17.300 dan bahan pendukung $R p$ 65.000. Produk rengginang jagung bahan penolong sebesar $\mathrm{Rp} 16.300$ dan bahan pendukung $\mathrm{Rp}$ 62.000. Produk emping jagung bahan penolongnya sebesar $\mathrm{Rp}$ 9.150 dan bahan pendukung Rp 65.000. Produk kripik ubi kayu bahan penolongnya sebesar Rp 2.925 dan bahan pendukung Rp 56.250.

Nilai tambah dari proses pengolahan komoditas pangan unggulan jagung dan ubi kayu per bahan baku, diperoleh produk tortilla jagung sebesar $\mathrm{Rp}$ $36.349 / \mathrm{kg}$, produk rengginang jagung sebesar $\mathrm{Rp} 32.330 / \mathrm{kg}$, produk emping jagung sebesar Rp 21.611/kg, dan produk kripik ubi kayu sebesar Rp 14.875/kg bahan baku.

\section{Saran}

Diharapkan kepada anggota kelompok pengolahan komoditas pangan unggulan melakukan proses produksi yang lebih efisien agar menghasilkan nilai tambah dan keuntungan yang lebih tinggi terutama berkaitan dengan penambahan tenaga kerja.

Kepada pemerintah atau instansi terkaiat diharapkan agar memberi tambahan pelatihan dan informasi yang lebih luas tentang pemasaran agroindustri pada kelompok pengolahan hasil pertanian di Kecamatan Selaparang Kota Mataram. Selalu menjaga jalinan kerjasama kemitraan antara pengusaha agroindustri dan pengusaha lokal dalam pemasaran hasil olahan komoditas unggulan. Perlu selalu memperbaiki teknik pengolahan komoditas pangan unggulan agar dapat meningkatkan pendapatan industri rumahtangga.

\section{DAFTAR PUSTAKA}

Disperindag, 2014. Rekapitulasi Sentra Industri Kecil Menengah Kab/Kota di NTB 2014. Kantor Perwakilan Mataram. Mataram.

Kementerian Pertanian, 2015. Strategi Induk Pembangunan Pertanian 2014-2045. Membangun PertanianBioindustri Berkelanjutan. Jakarta.

Said, G., 2005. Manajemen Agribisnis MMA. IPB. 
Saragih, B., 2004. Membangun Pertanian Perspektif Agribisnis. Dalam Pertanian Mandiri. Penebar Swadaya, Jakarta.

Soedianto, 1993. Agribisnis Seri IV. BPLP. Departemen Pertanian. Jakarta.

Soekartawai, 2002. Prinsip Dasar Ekonomi Pertanian Teori dan Aplikasi. Edisi Revisi. PT. Raja Grafindo. Jakarta.

Supriyati dan Herlina T., 2008. Pusat Analisis Sosial Ekonomi dan Kebijakan Pertanian. Warta Penelitian dan Pengembangan Pertanian, 30 (4). Bogor.

Suhendar, H., 2002. Analisis Nilai Tambah dan Strategi Pengembangan Industri Kecil Tahu Sumedang (Studi Kasus di Bogor, Jawa Barat). Makalah Penelitian Jurusan Ilmu-ilmu Sosial Ekonomi Pertanian Fakultas Pertanian IPB. Bogor.

Tarigan, R., 2004. Ekonomi Regional. Bumi Aksara, Jakarta. 